\title{
European Medicines Agency updates on the review of Pandemrix and reports of narcolepsy
}

Eurosurveillance editorial team (eurosurveillance@ecdc.europa.eu) ${ }^{1}$

1. European Centre for Disease Prevention and Control (ECDC), Stockholm, Sweden

Citation style for this article:

Eurosurveillance editorial team. European Medicines Agency updates on the review of Pandemrix and reports of narcolepsy. Euro Surveill. 2010;15(38):pii=19670.

Available online: http://www.eurosurveillance.org/ViewArticle.aspx?Articleld $=19670$

The European Medicines Agency's Committee for Medicinal Products for Human Use today 23 September 2010 announced that it has reviewed all available data on the suspected link between narcolepsy and Pandemrix and concludes that the available evidence is insufficient to determine whether there is any link between the illness and the vaccine.

The Committee agrees that further studies are necessary to understand the issue fully and that while the review is still ongoing there is no need for Europe-wide restrictions on the use of Pandemrix. The ongoing review will take some three to six months to conclude and will require new epidemiological research to establish conclusions on the possibility of a link between Pandemrix and narcolepsy.

Until mid-September there were 81 reports from healthcare professionals which suggested narcolepsy. Of these the majority came from Sweden (34) and Finland (30), 10 from France, six from Norway and one from Portugal.

To read more about the issue, please visit the website of the European Medicines Agency: www.ema.europa. eu. 